\title{
Efficient Rapid Microwave-Assisted Route to Synthesize Monodispersive Pt Nanoparticles and Their Electrocatalytic Activity for Methanol Oxidation
}

\author{
Libin Wang, ${ }^{1,2}$ Wenjun Xu, ${ }^{1}$ Xiao Wu, ${ }^{1}$ Qian Li, ${ }^{1}$ Zhiming Wang, ${ }^{1}$ and Xiuwen Zheng ${ }^{1,2}$ \\ ${ }^{1}$ School of Chemistry and Chemical Engineering, Linyi University, Linyi 276000, China \\ ${ }^{2}$ Key Laboratory of Resources \& Environmental Analytical Chemistry, University of Shandong, Linyi, Shandong 276000, China \\ Correspondence should be addressed to Libin Wang; wanglibin@lyu.edu.cn and Xiuwen Zheng; xwzheng1976@gmail.com
}

Received 15 November 2013; Accepted 13 April 2014; Published 4 May 2014

Academic Editor: Alireza Talebitaher

Copyright (C) 2014 Libin Wang et al. This is an open access article distributed under the Creative Commons Attribution License, which permits unrestricted use, distribution, and reproduction in any medium, provided the original work is properly cited.

\begin{abstract}
High monodispersive Pt nanoparticles (NPs) have been prepared via two facile and environmentally-friendly procedures, either through a traditional solvothermal route (T-Pt NPs) or via a microwave-assisted route (M-Pt NPs). The transmission electron microscopy (TEM) shows the high Monodispersity for T-Pt NPs with the average diameter being ca.2.79 nm and the pod-like nanostructure for M-Pt NPs, which indicate the efficiency of both methods. An optimal choice of protocol allows reducing the reaction time from 2 hours (T-Pt NPs) to 20 minutes (M-Pt NPs). The electrocatalytic activities of as-prepared Pt NPs were investigated by cyclic voltammetry, showing very high catalytic activity for a methanol oxidation reaction.
\end{abstract}

\section{Introduction}

Recently, synthesis of platinum NPs with controlled sizes and shapes has stimulated extensive research owing to its unusual physical and chemical properties in developing highly active Pt NPs for fuel cell reactions [1, 2], bioimaging [3], chemical sensors [4], drug carrier for drug delivery systems (DDS) [5], and so forth. Because of the high surface area, a large number of edges and corner atoms for Pt NPs, it is generally accepted that both catalytic efficiency and selectivity are highly dependent on the size and shape of the platinum material [6-8]. For instance, due to the high surface area and enough absorption sites, the three-dimensional (3D) dendritic platinum display high active as nanoelectrocatalyst for the reduction of dioxygen and oxidation of methanol [9]. Both Pt cubic nanoboxes and hollow spheres exist higher activity than their solid particles in oxygen reduction reaction or methanol oxidation reaction, indicating a strong shape-dependent catalytic property $[2,10]$. Therefore, it is imperative to develop synthetic routes to prepare nonagglomerated, uniform Pt NPs with a well-controlled size and a narrow size distribution. Up to date, serials methods have been developed to synthesize Pt NPs with desired morphologies in cube $[2,5]$, multioctahedral [11], dendritic [12], flower [13], and one-dimensional nanostructure [14]. Recently, the mesoporous structure of Pt NPs becomes one of the hot research topics and obtains considerable progresses by Yamauchi group [15-17]. And also, serials of alloy or coreshell Pt NPs have also been synthesized [18, 19]. Despite this, developing a reliable, facile, and environmentally-friendly strategy for the production of high mondispersive Pt NPs still remains a challenge.

Herein, two facile and environmentally-friendly procedures were proposed to synthesize high mondispersive $\mathrm{Pt}$ NPs, either through a traditional solvothermal route (T$\mathrm{Pt} \mathrm{NPs}$ ) or via a microwave-assisted route (M-Pt NPs). Microwave-assisted synthesis is a relatively new chemical method to accelerate chemical reactions, which have been widely applied in the nanomaterials preparation [20-23]. The use of the microwave-assisted route has several advantages over other existing methods in terms of energy efficiency and shorter reaction time from hours to minutes. Compared to the previous polyol synthesis route, the water-based system can provide a more environmentally benign route to the synthesis of Pt NPs, because it does not involve toxic organic solvents. 


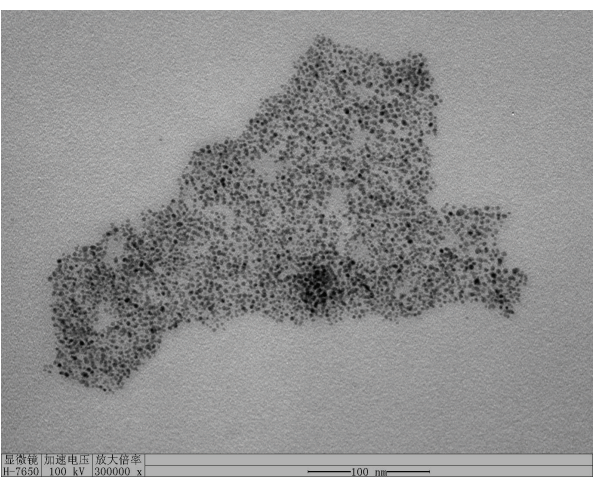

(a)

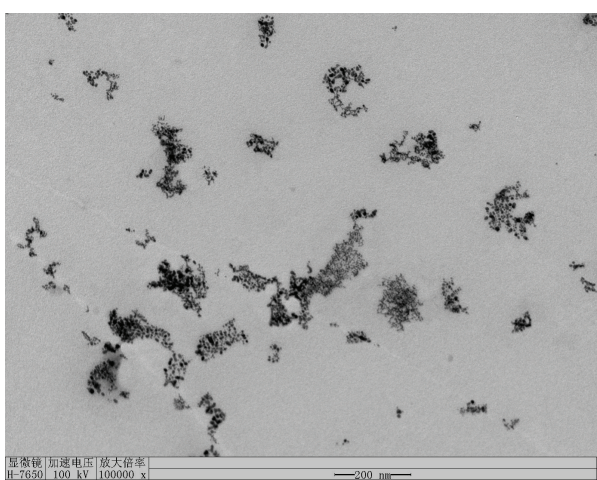

(c)

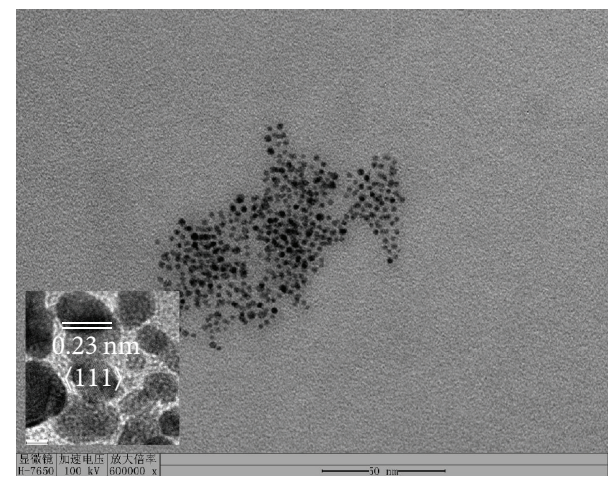

(b)

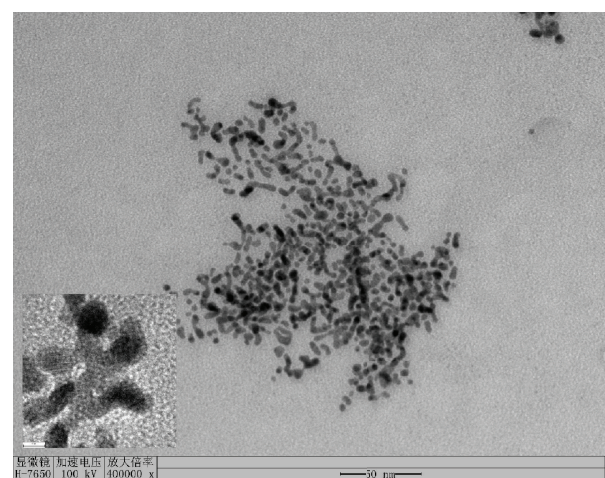

(d)

Figure 1: TEM images of as-prepared Pt NPs with different magnification for (a-b) T-Pt NPs and (c-d) M-Pt NPs.

\section{Experimental Section}

In a typical synthesis, PVP $\sim 0.0025 \mathrm{mmol})$ was completely dispersed into $15 \mathrm{~mL}$ distilled water with the assistance of ultrasound irradiation. After that, $\mathrm{H}_{2} \mathrm{PtCl}_{6} \cdot 6 \mathrm{H}_{2} \mathrm{O}$ dispersed in ethylene glycol (EG) solution $\left(7 \mathrm{~mL}, 9.65 \times 10^{-6} \mathrm{~mol} / \mathrm{mL}\right)$ was added into the aforementioned aqueous solution under the sonication. For solvothermal route, the mixed solution was loaded into the $50 \mathrm{~mL}$ Teflon lined autoclave, which was maintained at $200^{\circ} \mathrm{C}$ for $2 \mathrm{~h}$. For microwave-assisted route, the microwave-assisted reactions were carried out in a focused single-mode microwave synthesis system (Discover, CEM, $2.45 \mathrm{GHz}, 300 \mathrm{~W}$ ). Reactions at elevated pressure and temperature were performed in $10 \mathrm{~mL}$ vial, and the temperature was accurately controlled by automatic adjusting of microwave power at $200^{\circ} \mathrm{C}$ for $20 \mathrm{~min}$. After reactions, the products were cooled down to room temperature. The final products were collected by centrifugation, washed several times with water and ethanol, and dried at $50^{\circ} \mathrm{C}$ under vacuum condition. The samples are designated as T-Pt NPs for solvothermal procedures and M-Pt NPs for microwaveassisted reaction.

The morphology and composition of the products were analyzed by transmission electron microscopy (TEM) and $\mathrm{X}$-ray powder diffraction patterns (XRD), which were conducted on an H-7650 and Bruker D8 ADVANCE X-ray powder diffractometer with GADDS HTS and $\mathrm{Cu} \mathrm{K} \alpha$ radiation $(\lambda=0.154184 \mathrm{~nm})$. Electrochemical measurements are per- formed on an Epsilon/100BWBAS electrochemical working system. A glassy carbon electrode modified with Pt NPs is employed as working electrode. A platinum foil is served as the counter electrode and a saturated calomel electrode (SCE) is used as the reference electrode.

\section{Results and Discussion}

Figures $1(\mathrm{a})$ and $1(\mathrm{~b})$ are the typical TEM images for TPt NPs with different magnification, indicating the high monodispersity for as-prepared products. Inserted is the high resolution TEM (HRTEM) image of a single Pt NPs, displaying a single crystal nature for T-Pt NPs. The fringes with lattice spacing of $0.23 \mathrm{~nm}$ can be indexed as $\{111\}$ of facecentered cubic (fcc) Pt. Figures 1(c) and 1(d) are the TEM images for M-Pt NPs, showing the pod-like nanostructure. A few NPs display the multiarm nanostructure. HRTEM studies (Figure 1(d), inserted) show that these nanopods have lattice fringes of $0.23 \mathrm{~nm}$, corresponding to the interplane distance of $\{111\}$ planes in fcc-Pt. The crystalline nature of the Pt nanopods suggests that these nanocrystals were formed through an overgrowth mechanism rather than the random aggregation of small nanocrystals [10], which is due to the rapid heating and shorter reaction time function of microwave irradiation. The mean diameter for T-Pt NPs is $2.79 \mathrm{~nm}$ (Figure 2(a)), which is consistent with the HRTEM results (Figure 1(b), inserted). Based on Figure 1, 


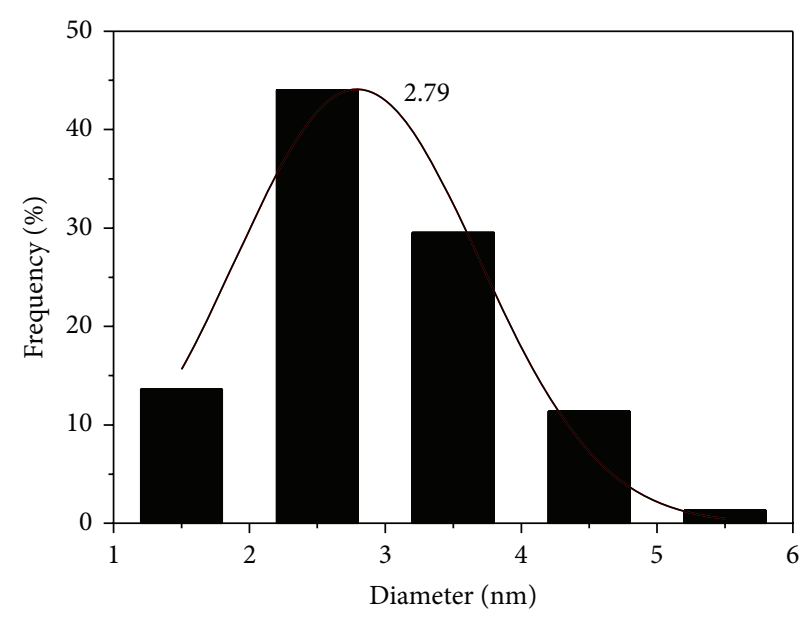

(a)

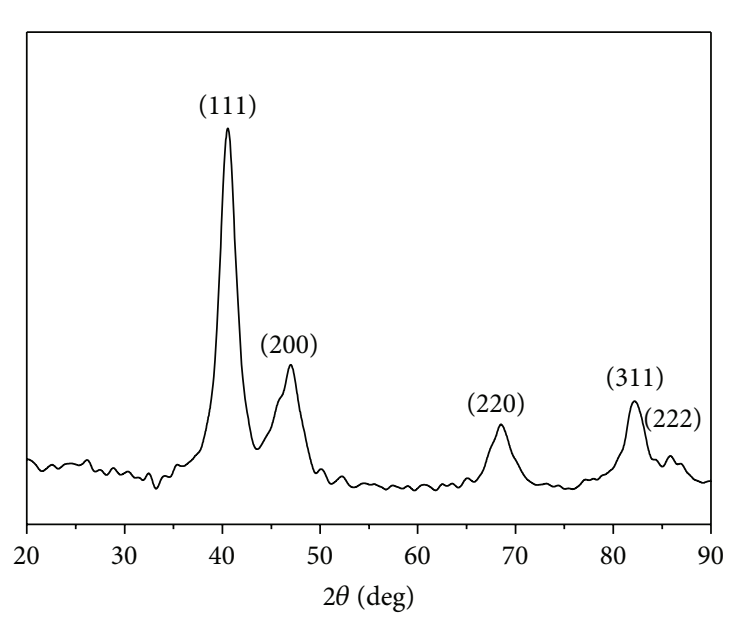

(b)

FIgURE 2: (a) The statistical result of size distribution for T-Pt NPs, (b) XRD pattern for as-prepared T-Pt NPs.

one could find that both the traditional solvothermal route and microwave-assisted route are effective routes for the synthesis of high monodispersive $\mathrm{Pt}$ nanoparticles via the given experimental conditions. However, for microwaveassisted route, the reaction time was reduced from 2 hours (T-Pt NPs) to 20 minutes (M-Pt NPs), indicating the reduced energy consumption. The XRD pattern of as-prepared $\mathrm{Pt}$ NPs is shown in Figure 2(b). The diffraction peaks at 39.8, $46.2,67.5,81.3$, and 85.88 can be assigned to reflections from the (111), (200), (220), (311), and (222) planes of the facecentered cubic (fcc) Pt. The average size of the Pt NPs is $3.1 \mathrm{~nm}$, calculated by the Debye-Scherrer formula on the basis of the $\mathrm{Pt}$ (111) plane, which coincides with the result from the Pt NPs size distribution histogram in the error (Figure 2(a)).

In the water-based system, contrast experiments were carried out in detail to obtain universal protocols for high mondispersive Pt NPs. Keeping the other experimental conditions constant, it is not easy to obtain the ideal result using sodium oleate instead of PVP. However, high monodispersive Pt NPs could be obtained using ascorbic acid as reducing agent at appropriate sodium oleate concentration. For this system, $\mathrm{H}_{2} \mathrm{PtCl}_{6} \cdot 6 \mathrm{H}_{2} \mathrm{O}$ was firstly dispersed in distilled water rather than EG solution $\left(9.65 \times 10^{-6} \mathrm{~mol} / \mathrm{mL}\right)$. At optimal conditions $\left(2.7 \times 10^{-5} \mathrm{~mol} / \mathrm{mL}\right.$ for sodium oleate, $6.7 \times$ $10^{-7} \mathrm{~mol} / \mathrm{mL}$ for ascorbic acid), both samples show high monodispersive nature with average ca. $3 \mathrm{~nm}$ for T-Pt (Figures 3(a) and 3(b)) NPs and ca.2.4 nm for M-Pt NPs (Figures 3(c) and $3(\mathrm{~d})$ ), respectively. Based on Figure 3, one could see that there is no obvious difference for the as-prepared Pt NPs via the solvothermal (T-Pt NPs) and microwave-assisted routes. In order to further understand the influence of concentration of surfactants on Pt NPs growth, the process was carried out with different sodium oleate concentrations. It is found that the aggregative Pt NPs (not shown here) could be obtained if the surfactant concentration was decreased down to $2.7 \times$ $10^{-6} \mathrm{~mol} / \mathrm{mL}$.

Electrocatalytic activity of the Pt NPs toward methanol oxidation reaction (MOR) was studied by cyclic voltammetry in a nitrogen-saturated $0.5 \mathrm{M} \mathrm{CH}_{3} \mathrm{OH}-0.5 \mathrm{M} \mathrm{H}_{2} \mathrm{SO}_{4}$ solution at a scan rate of $50 \mathrm{mV} \mathrm{s}^{-1}$, and the $\mathrm{CV}$ curves are shown in Figure 4. Line a is the cure on behalf of the bare glassy carbon electrode in $0.5 \mathrm{M} \mathrm{H}_{2} \mathrm{SO}_{4}$ solution. Line $\mathrm{b}$ is representative of bare glassy carbon electrode in $0.5 \mathrm{M} \mathrm{H}_{2} \mathrm{SO}_{4}$ and $0.5 \mathrm{M}$ $\mathrm{CH}_{3} \mathrm{OH}$ mixed solution. Line $\mathrm{c}$ stands for Pt NPs modified glassy carbon electrode in $0.5 \mathrm{M} \mathrm{H}_{2} \mathrm{SO}_{4}$ and $0.5 \mathrm{M} \mathrm{CH}_{3} \mathrm{OH}$ mixed solution. Compared with lines a and $b$, it can be seen from line $\mathrm{c}$ that there is a strong peak at $0.68 \mathrm{~V}$, which is the oxidation peak of $\mathrm{CH}_{3} \mathrm{OH}$ oxidized to $\mathrm{HCHO}$. The peak at $0.39 \mathrm{~V}$ should be primarily attributed to the removal of the residual carbon species, such as $\mathrm{CO}_{\text {ads }}$, formed in the forward scan. The peak ratios between positive and negative scans are ca.1.8, indicating relatively complete oxidation of methanol to carbon dioxide [24]. All these results confirmed the high catalytic activity of as-prepared Pt NPs for MOR.

Here, the efficiencies of two methods of synthesizing monodispersive Pt NPs are compared using the ethylene glycol as reducing agent, either through a traditional solvothermal procedure or via microwave-assisted method. It is well known that microwave irradiation provides rapid and uniform heating of reagents, solvents, and intermediates. This rapid MW heating also provides uniform nucleation and growth conditions, leading to homogeneous nanomaterials with smaller sizes [20-23]. In the polyol reactions, EG was as a sacrificial reductant of $\mathrm{Pt}$ ions according to the following mechanism [25]:

$$
\begin{gathered}
\mathrm{CH}_{2} \mathrm{OHCH}_{2} \mathrm{OH} \longrightarrow \mathrm{CH}_{3} \mathrm{CHO}+\mathrm{H}_{2} \mathrm{O} \\
\mathrm{CH}_{3} \mathrm{CHO}+\mathrm{PtCl}_{6}{ }^{2-} \longrightarrow \mathrm{CH}_{3} \mathrm{COCOCH}_{3}+\mathrm{H}_{2} \mathrm{O}+\mathrm{Pt}
\end{gathered}
$$

Firstly, EG was rapidly changed into $\mathrm{CH}_{3} \mathrm{CHO}$ up to given temperature; simultaneously the $\mathrm{Pt}$ metallic ions are reduced to metallic Pt NPs by $\mathrm{CH}_{3} \mathrm{CHO}$.

\section{Conclusion}

A universal water-based protocol was developed to synthesize high monodispersive Pt NPs with spherical or podlike shape, using a traditional solvothermal route or via a 


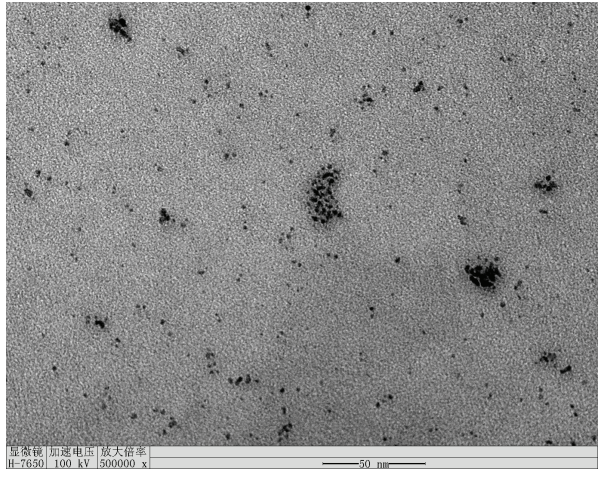

(a)

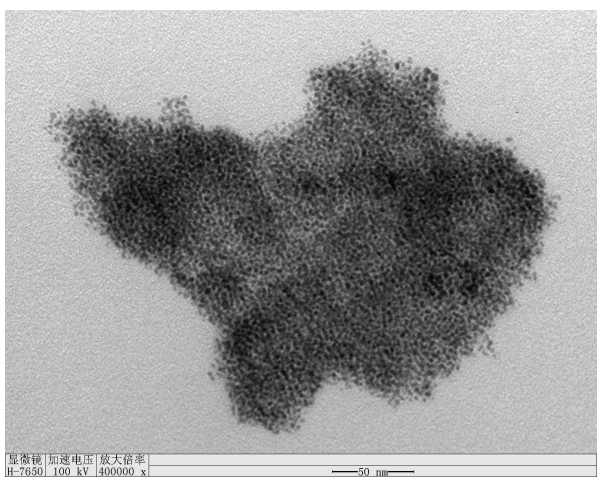

(c)

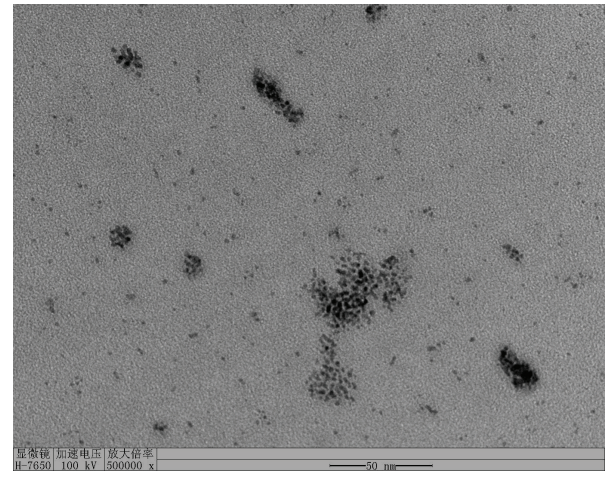

(b)

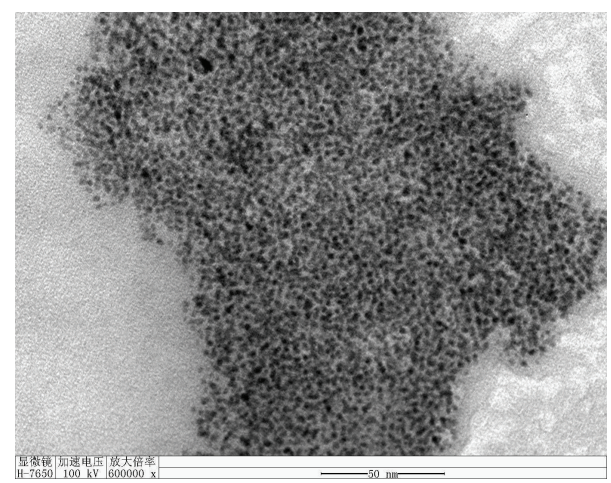

(d)

Figure 3: TEM images of as-prepared Pt NPs with different magnification for (a-b) M-Pt NPs and (c-d) T-Pt NPs using sodium oleate as surfactant and ascorbic acid as reducing agent.

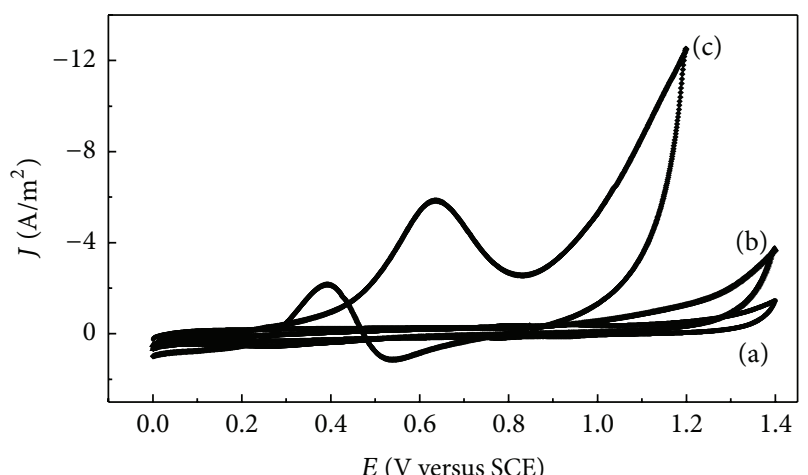

- (a) Bare GC electrode in $0.5 \mathrm{M} \mathrm{H}_{2} \mathrm{SO}_{4}$

$\rightarrow$ (b) Bare GC electrode in $0.5 \mathrm{M} \mathrm{H}_{2} \mathrm{SO}_{4}+\mathrm{CH}_{3} \mathrm{OH}$

$\rightarrow$ (c) GC electrode modified with Pt NPs in $0.5 \mathrm{M}$ $\mathrm{H}_{2} \mathrm{SO}_{4}+\mathrm{CH}_{3} \mathrm{OH}$

Figure 4: CVs of the Pt NPs (the potential was applied with a scanning rate of $50 \mathrm{mVs}^{-1}$ ).

microwave-assisted route. Due to the rapid heating from microwave irradiation, the overgrowth of Pt nanocrystals results in the pod-like morphology for M-Pt NPs. However, the microwave-assisted route is the more efficient method to overcome tedious and time-consuming process and reduces the reaction time from several hours to several minutes. CVs confirmed the high catalytic activity of as-prepared Pt NPs for MOR.

\section{Conflict of Interests}

The authors declare that there is no conflict of interests regarding the publication of this paper.

\section{Acknowledgment}

This work was supported by the National Natural Science Foundation of China (nos. 21101087, 21375057, and 21205057) and Shandong Province Natural Science Foundation (no. ZR2010BQ030).

\section{References}

[1] Y. J. Kang, J. B. Pyo, X. C. Ye, T. R. Gordon, and C. B. Murray, "Synthesis, shape control, and methanol electro-oxidation properties of Pt-Zn alloy and Pt3Zn intermetallic nanocrystals," ACS Nano, vol. 6, pp. 5642-5647, 2012.

[2] Z. M. Peng, H. J. You, J. B. Wu, and H. Yang, "Electrochemical synthesis and catalytic property of sub-10 $\mathrm{nm}$ platinum cubic nanoboxes," Nano Letters, vol. 10, pp. 1492-1496, 2010.

[3] S.-I. Tanaka, J. Miyazaki, D. K. Tiwari, T. Jin, and Y. Inouye, "Fluorescent platinum nanoclusters: synthesis, purification, characterization, and application to bioimaging," Angewandte Chemie, vol. 50, no. 2, pp. 431-435, 2011.

[4] S. Guo, D. Wen, Y. Zhai, S. Dong, and E. Wang, "Platinum nanoparticle ensemble-on-graphene hybrid nanosheet: one-pot, rapid synthesis, and used as new electrode material for electrochemical sensing," ACS Nano, vol. 4, no. 7, pp. 3959-3968, 2010. 
[5] C. Y. Hong, Y. Yamauchi, and K. C. W. Wu, "In vitro cytotoxicity and intracellular bioimaging of dendritic platinum nanoparticles by differential interference contrast (DIC)," Chemistry Letters, vol. 40, pp. 408-409, 2011.

[6] M. N. Mankin, V. Mazumder, and S. Sun, "One-pot synthesis of Pt nanocubes and nanopods via burst nucleation and controlled secondary growth," Chemistry of Materials, vol. 23, no. 2, pp. 132-136, 2011.

[7] C. Wang, H. Daimon, T. Onodera, T. Koda, and S. Sun, "A general approach to the size- and shape-controlled synthesis of platinum nanoparticles and their catalytic reduction of oxygen," Angewandte Chemie, vol. 47, no. 19, pp. 3588-3591, 2008.

[8] C. Koenigsmann, W.-P. Zhou, R. R. Adzic, E. Sutter, and S. S. Wong, "Size-dependent enhancement of electrocatalytic performance in relatively defect-free, processed ultrathin platinum nanowires," Nano Letters, vol. 10, no. 8, pp. 2806-2811, 2010.

[9] L. Wang and Y. Yamauchi, "Facile synthesis of three-dimensional dendritic platinum nanoelectrocatalyst," Chemistry of Materials, vol. 21, no. 15, pp. 3562-3569, 2009.

[10] S. J. Guo, S. J. Dong, and E. Wang, "A general method for the rapid synthesis of hollow metallic or bimetallic nanoelectrocatalysts with urchinlike morphology," Chemistry, vol. 14, pp. 4689-4695, 2008.

[11] B. Lim, X. Lu, M. Jiang et al., "Facile synthesis of highly faceted multioctahedral Pt nanocrystals through controlled overgrowth," Nano Letters, vol. 8, no. 11, pp. 4043-4047, 2008.

[12] L. Wang, H. Wang, Y. Nemoto, and Y. Yamauchi, "Rapid and efficient synthesis of platinum nanodendrites with high surface area by chemical reduction with formic acid," Chemistry of Materials, vol. 22, no. 9, pp. 2835-2841, 2010.

[13] J. N. Tiwari, F.-M. Pan, and K.-L. Lin, "Facile approach to the synthesis of 3D platinum nanoflowers and their electrochemical characteristics," New Journal of Chemistry, vol. 33, no. 7, pp. 1482-1485, 2009.

[14] L. C. Liu, S. H. Yoo, and S. Park, "Synthesis of vertically aligned hollow platinum nanotubes with single crystalline nanoflakes," Chemistry of Materials, vol. 22, pp. 2681-2684, 2010.

[15] Y. Yamauchi, "Field-Induced alignment controls of one-dimensional mesochannels in mesoporous materials," Journal of the Ceramic Society of Japan, vol. 121, no. 1417, pp. 831-840, 2013.

[16] H. Wang, H. Y. Jeong, M. Imura et al., "Shape- and size-controlled synthesis in hard templates: sophisticated chemical reduction for mesoporous monocrystalline platinum nanoparticles," Journal of the American Chemical Society, vol. 133, no. 37, pp. 14526-14529, 2011.

[17] H. J. Wang, L. Wang, T. Sato et al., "Synthesis of mesoporous Pt films with tunable pore sizes from aqueous surfactant solutions," Chemistry of Materials, vol. 24, pp. 1591-1598, 2012.

[18] C. L. Li and Y. Yamauchi, "Facile solution synthesis of Ag@Pt core-shell nanoparticles with dendritic Pt shells," Physical Chemistry Chemical Physics, vol. 15, pp. 3490-3496, 2013.

[19] L. Wang and Y. Yamauchi, "Controlled aqueous solution synthesis of platinum-palladium alloy nanodendrites with various compositions using amphiphilic triblock copolymers," Chemistry, vol. 5, no. 12, pp. 2493-2498, 2010.

[20] X. W. Zheng, Q. T. Hu, and C. H. Sun, "Efficient rapid microwave-assisted route to synthesize InP micrometer hollow spheres," Materials Research Bulletin, vol. 44, pp. 216-219, 2009.

[21] R. Eluri and B. Paul, "Microwave assisted greener synthesis of nickel nanoparticles using sodium hypophosphite," Materials Letters, vol. 76, pp. 36-39, 2012.
[22] K. D. Bhatte, D. N. Sawant, R. A. Watile, and B. M. Bhanage, "A rapid, one step microwave assisted synthesis of nanosize zinc oxide," Materials Letters, vol. 69, pp. 66-68, 2012.

[23] H. Wang, L. Wang, Y. Nemoto, N. Suzuki, and Y. Yamauchi, "Microwave-assisted rapid synthesis of platinum nanoclusters with high surface area," Journal of Nanoscience and Nanotechnology, vol. 10, no. 10, pp. 6489-6494, 2010.

[24] Y. Lin, X. Cui, C. H. Yen, and C. M. Wai, "PtRu/carbon nanotube nanocomposite synthesized in supercritical fluid: a novel electrocatalyst for direct methanol fuel cells," Langmuir, vol. 21, no. 24, pp. 11474-11479, 2005.

[25] R. Harpeness and A. Gedanken, "Microwave synthesis of coreshell gold/palladium bimetallic nanoparticles," Langmuir, vol. 20, no. 8, pp. 3431-3434, 2004. 

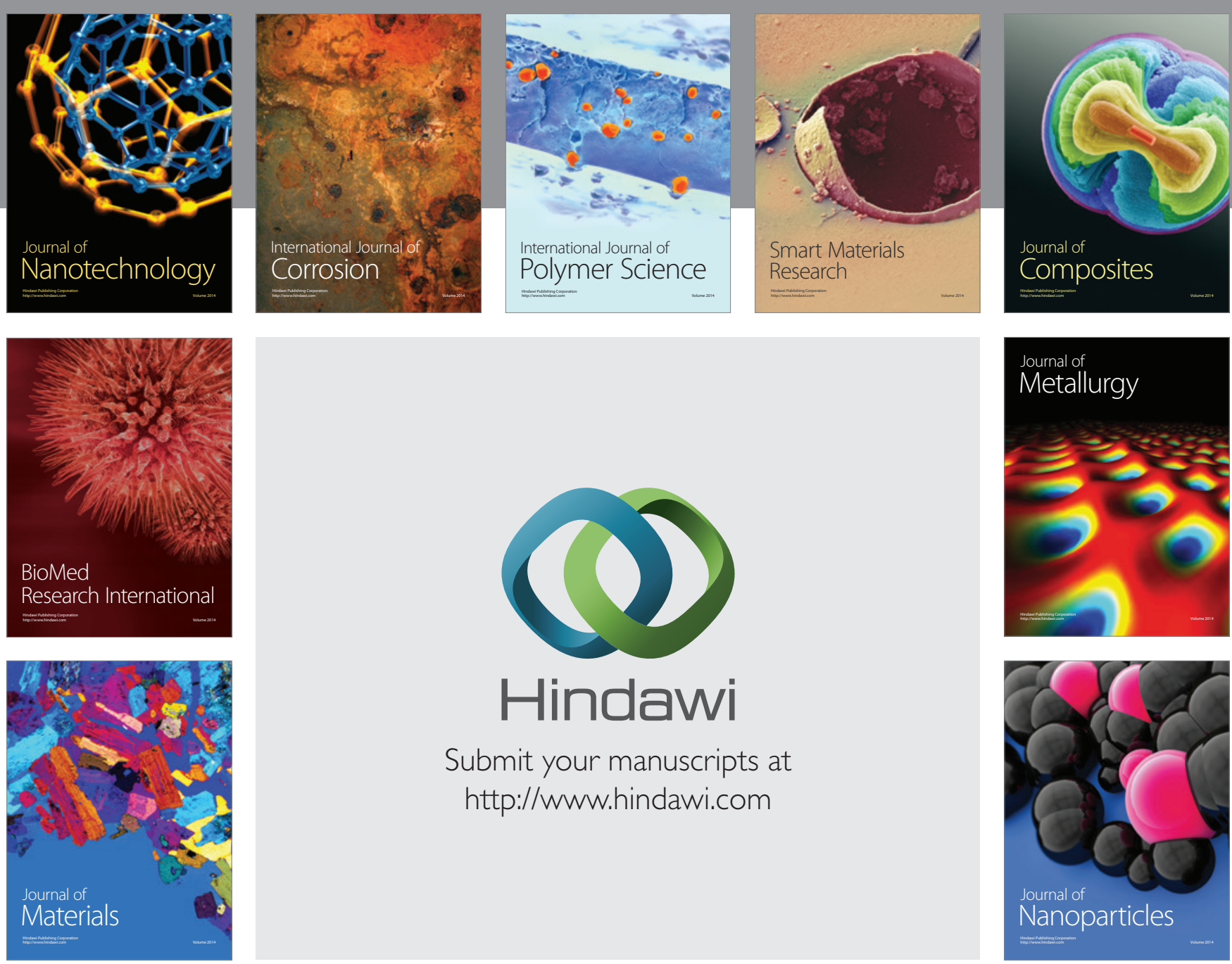

Submit your manuscripts at http://www.hindawi.com
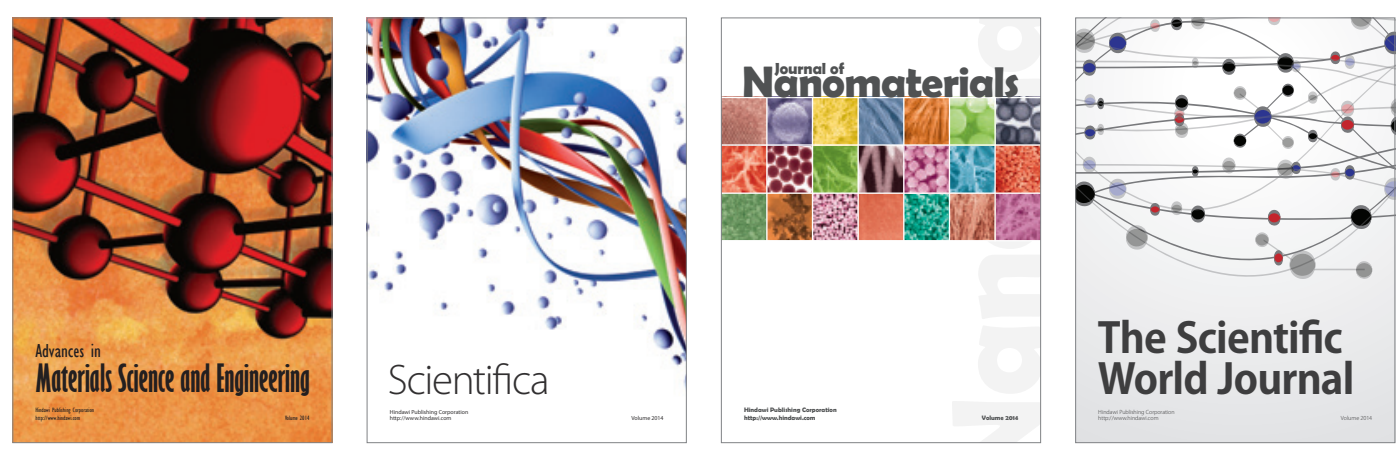

\section{The Scientific World Journal}
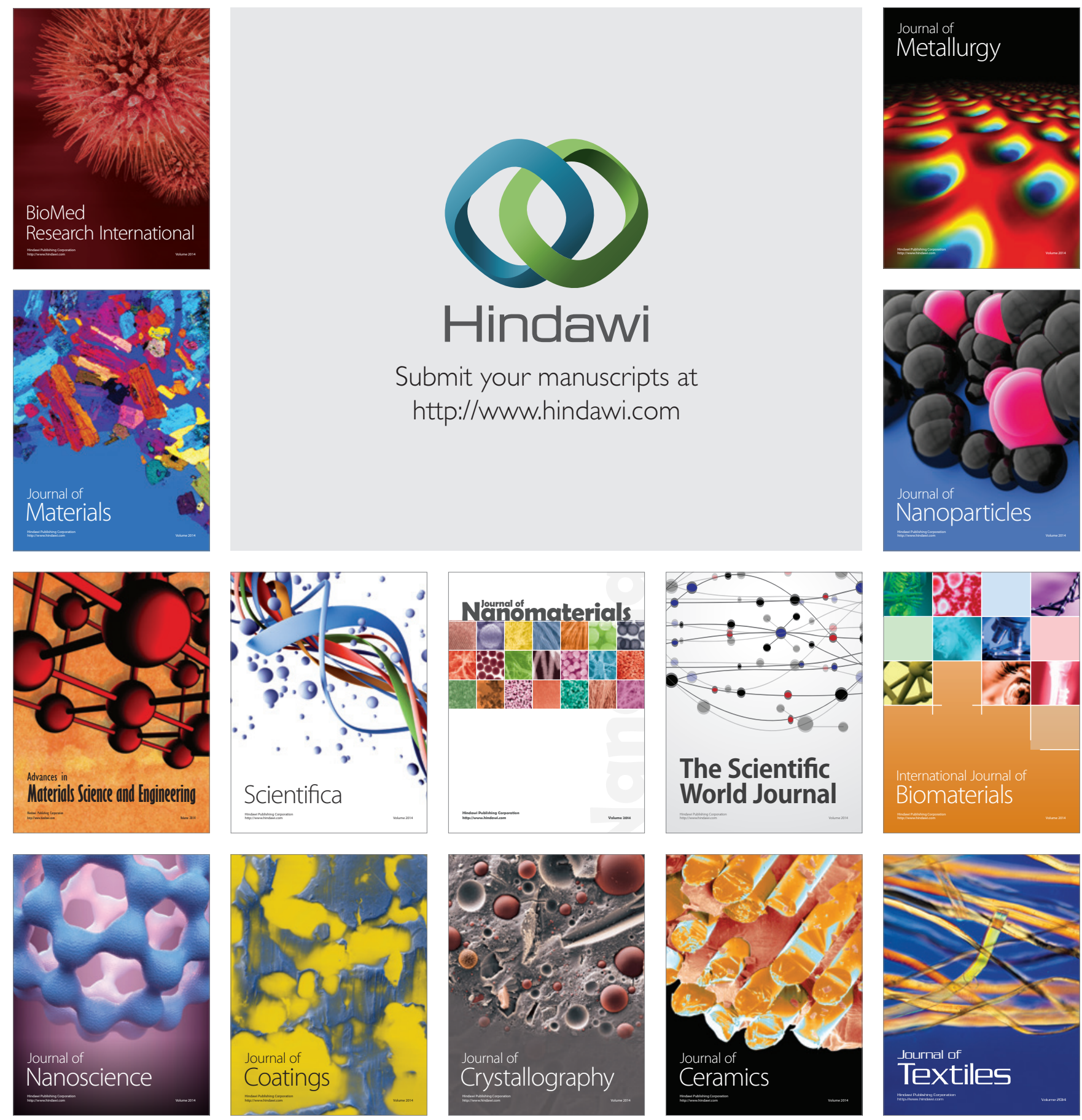